\title{
Die Xerosis der Conjunctiva und Cornea kleiner Kinder.
}

\author{
Vorläufige Mittheilung \\ von \\ Prof. Th. Leber in Göttingen.
}

Unter dem Namen „Hornhautverschwärung bei infantiler Encephalitis" hat bekanntlich v. Graefe eine mit Xerosis verbundene Hornhautvereiterung bei kleinen Kindern beschrieben, die fast regelmässig zum Tode führt und deren Entstehung er auf eine von Virchow aufgestellte Form von Encephalitis zurückzuführen geneigt war. Seitdem hat Jastrowitz gezeigt, dass das dieser Annahme zu Grunde liegende Verhalten des Gehirns, auffallende röthliche Färbung der weissen Substanz und reichlicher Gehalt derselben an Fettkornchenzellen, in den ersten Lebensmonaten nicht ohne Weiteres als pathologiseh betrachtet werden darf. Da überdies bei dieser infantilen Xerosis Cerebralerscheinungen im Allgemeinen fehlen, so unterliegt es jetzt wohl keinem Zweifel mehr, dass sie nicht auf ein Gehirnleiden zurückzuführen ist. Auch liegt zur Zeit wohl kein genügender Grund mehr vor, sie von der sonst bekannten, ächten Xerosis des Auges zu trennen, indem ein etwaiges Vorhandensein ron Hemeralopie bei 
so kleinen Kindern nicht zu constatiren ist und der ungewöhnlich schwere Verlauf durch das zarte Alter und durch Intestinal- und Lungencomplicationen wohl erklärt wird. Auch die Mittheilungen $H$. de Gouvêa's in diesem Hefte über die in Brasilien vorkommenden Fälle, wo die Krankheit besonders häufig und schwer auftritt, sprechen sehr für die letztere, anch von diesem Autor vertretene Ansicht.

Als Ursache der Krankheit wird gewöhnlich mangelhafte Ernährung angegeben, allein die Ernährungsstörung tritt zuweilen sicher erst im Verlanf der Krankheit anf und genügt auch wobl für sich allein nicht zur Erklärung eines so schweren localen Ulcerationsprocesses. Horner beobachtete bei einem von ihm hierher gerechneten Fall eine mycotische Infiltration des Geschwürsgrundes der Hornhaut, hält aber die Spaltpilze nicht für die Krankheitserreger, sondern glaubt, dass sie sich erst secundär auf der durch mangelhaften Lidschluss vertrockneten Hornhautoberfläche angesiedelt hätten.

Dagegen haben vor Kurzem Kuschbert u. Neisser *) bei der mit Hemeralopie verbundenen Xerosis der Bindehaut in einer grösseren Zahl von Fällen constant ein reichliches Vorkommen von Bacillen auf der veränderten Conjunctiva beobachtet and mit grosser Wahrseheinlichkeit die parasitäre Natur dieser Krankheit dargethan. Ich selbst bin durch Untersuchung eines Falles von infantiler Xerosis mit Hornhautvereiterung, welcher letal endigte, zu derselben Ansicht gelangt; da die ausführlichere Mittheilung meiner Beobachtungen erst im nächsten Hefte dieses Archivs erfolgen kann, so theile ich hier die wesentlichsten Ergebnisse derselben vorlänfig mit.

1. Die Zellplatten des desquamirenden Conjunetivalepithels waren in reichlichster Menge bedeckt, oft voll-

*) Verhandl. d. med. Sect. d. schles. Ges, f. vaterl. Kultur. Bresl. ärztl. Zeitschr. 24. Febr. 1883. 
ständig überzogen von eigenthümlichen, theils stäbchen-, theils cokkenförmigen Spaltpilzen. Dieselben Pilze fanden sich auch in dem Belag des Hornhautgeschwüres, sowie nach dem Tode - im Innern der total vereiterten Bulbi.

2. Einfuhr reichlicher Mengen der auf geeigneter Nährgelatine gezüchteten Pilze in den Conjunotivalsack vom Kaninchen, ohne Verletzung, bewirlten eine schwere ulceröse Hornhautaffection, die einige Tage fortschritt und dann zur Heilung kam. In der Hornhautsubstanz fanden sich kleine sternförmige Kolonien derselben Spaltpilze.

3. Mangelhafte Ernährung konnte in dem vorliegenden Falle nicht als Ursache der Krankheit gelten, weil das Kind erst mit dem Auftreten des Augenleidens anfing in der Ernährung zurückzugehen; ebenso wenig konnte die Ansiedelung der Pilze durch vorhergegangene Vertrocknung des Anges verursacht sein, denn der Lidschluss war ungestört und die Lider wurden vom Beginn der Augenentzundung an dauernd geschlossen gehalter.

4. Der Tod des (4monatlichen) Kindes erfolgte durch Bronchopneumonie nach vorausgegangenen Durchfällen und Erbrechen. Das Gehirn erwies sich bei der von Professor $0 \mathrm{rth}$ gemachten Section vollkommen normal. Dagegen fand sich im Nierenbecken, sowohl an den Papillen als den Kelchen, eine desquamirende Epithelaffection, die ganz mit der Xerosis der Conjunctiva übereinstimmte, auch genau mit denselben Spaltpilzen, so dass die Präparate von beiden Localitäten nicht zu unterscheiden waren. Die Nieren selbst boten keine auffallenden Veränderungen dar. Es liegt nahe, zn vermuthen, dass die Veränderung im Nierenbecken secundär, durch eine Ausscheidungsinfection entstanden war. 